\title{
EFFECT OF VERTICAL DISTRIBUTION OF MASS AND TRANSLATIONAL STIFFNESS ON DYNAMIC ECCENTRICITIES FOR A SPECIAL CLASS OF MULTI-STOREY BUILDINGS
}

\author{
G. L. Hutchinson', A. M. Chandler ${ }^{2}$ and M. A. Rady ${ }^{1}$ \\ This paper was presented at the \\ Pacific Conference on Earthquake Engineering, \\ New Zealand November 1991
}

\begin{abstract}
SUMMARY
The results from analyses which considered dynamic torsional coupling in single storey buildings have commonly been extrapolated to a special class of multi-storey buildings. Recently developed probabilistic methods are used in this paper to study the influence of various realistic vertical mass and stiffness distributions on the characteristics of torsional coupling in multi-storey buildings. Qualitative and quantitative differences between the results for single and multi-storey models are identified.
\end{abstract}

\section{INTRODUCTION}

The key parameters affecting the seismic response of torsionally coupled buildings have been well established from consideration of idealised single storey structural models $[1,2,12]$. These studies were limited by the assumption that their results are also valid, in both qualitative and quantitative terms, for a certain special class of multi-storey buildings $[5,6,10,11]$. The distribution of the structural properties of the special class of buildings is such that the loci of the storey centres of mass and rigidity lie on two vertical straight lines, and that the distributions of the storey translational and torsional stiffnesses are proportional. Aspects of the validity of the extrapolation from results of single storey models to multi-storey cases are considered in this paper. In particular, the effect of various realistic vertical distributions of mass and stiffness are examined, with a view to establishing a combination of these distributions which may be used for more extended parametric studies of torsional coupling in multi-storey models with vertical irregularities [3].

The results for an idealised 20-storey building model with the above eccentricity characteristics are presented in this study. A further detailed parametric study including evaluation of appropriate design provisions is in preparation [4]. References [3] and [4] include comparative results for single and multistorey buildings with $5,10,15$ and 20 floors. The effect of irregular vertical distributions of static stiffness eccentricities are also considered [3].

In the following sections the analytical techniques are summarised and the salient dynamic properties are specified. A comparison of torsional coupling effects for representative 20storey buildings are presented and the implications for further parametric studies are considered.

${ }^{1}$ The University of Melbourne, Australia

${ }^{2}$ University College London, UK(Member)

\section{Ground Motion Model}

Probabilistic normalised power spectrum methods for seismic analysis have been extended [7] to allow for uncertainty in ground motion intensity and its correlation with ground motion frequency content. This new method involving the intensitycorrelated probabilistic power spectrum (ICPPS) was used [8] to confirm that earlier findings relating to torsional coupling effects in single storey models are also valid for the generalised and more realistic earthquake representation offered by the probabilistic approach. In this study the ICPPS method is employed to establish the extent to which the general trends previously observed for simple single storey systems can be extrapolated to a representative 20 -storey structure with and without vertical mass and stiffness irregularities.

\section{Analytical Model}

In this paper, a representative shear beam building model of 20 storeys $(\mathrm{N}=20)$ is idealised by a partially symmetric multistorey structure (Fig. 1) with rigid floor diaphragms. The static eccentricity, $e_{i}$, is defined as the distance between the centres of mass and stiffness at that floor; the latter point may (for the special class of buildings studied herein), or may not be the same as the centres of rigidity $[9,11]$ and rotation. For this special class of building, $e_{i}$ equals a constant e $(i=1,2, \ldots$, $\mathrm{N}=20$ ), where $\mathrm{e}$ is a characteristic value for defining the structural eccentricity of the building. As illustrated in Fig.1, the centres of stiffness need not lie on the same vertical line. It is noted, however, that the emphasis in the present paper is on buildings with centres of stiffness and centres of mass lying on two parallel vertical lines. The ith floor translational stiffness $\mathrm{K}_{\mathrm{xi}}$ and torsional stiffness $\mathrm{K}_{\mathrm{ei}}$ taken about the centre of mass (or $\mathrm{K}_{\mathrm{esi}}$, taken about the centre of stiffness), together with the static stiffness eccentricity $e_{i}$, are defined for each level on a floor-tofloor basis. 


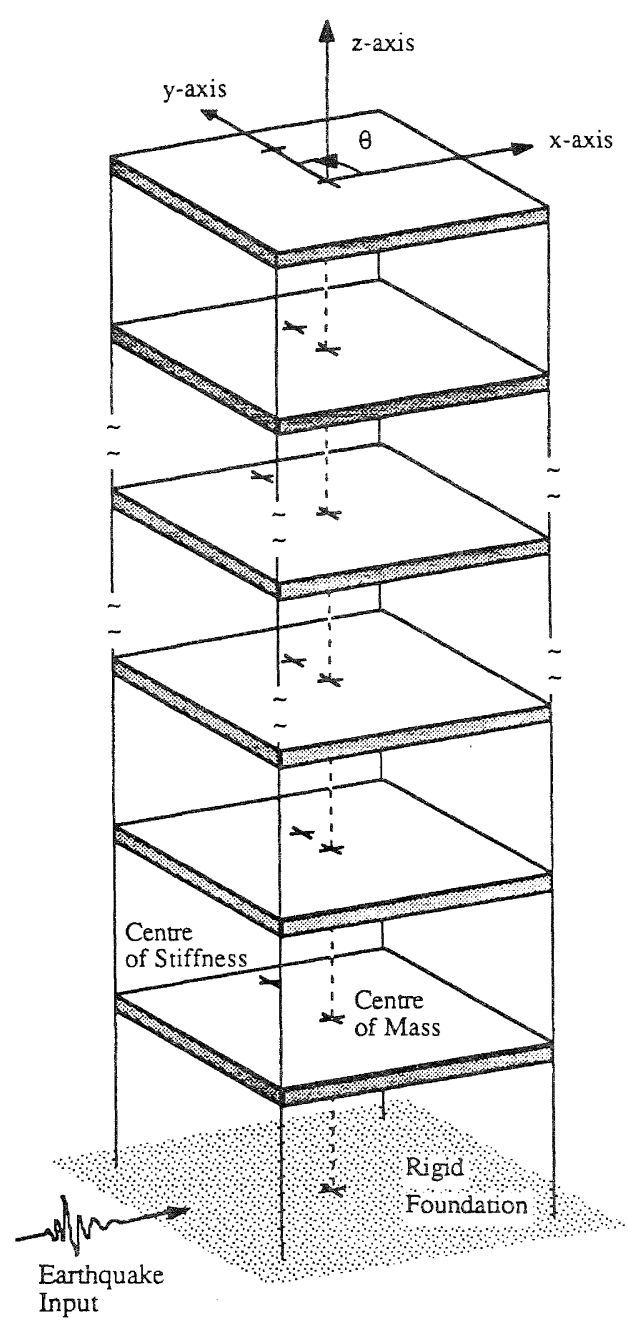

Figure 1 Idealised multi-storey building model.

The building model shown in Fig. 1 is subjected to a unidirectional earthquake base motion which is applied uniformly (across the $y$-axis of the structure) in the $x$-direction. Consequently each floor $i$ has two degrees of freedom, a translation in the $\mathrm{x}$-direction, $\mathrm{u}_{\mathrm{xi}}$, and a rotation, $\mathrm{u}_{\theta \mathrm{i}}$, about the centre of mass for that floor.

\section{Normalised Mass and Stiffness Distributions}

For this study, the vertical distributions of floor mass and storey stiffnesses are expressed in the following dimensionless forms: $\mu_{\mathrm{i}}=\mathrm{m}_{\mathrm{i}} / \mathrm{m}_{1}$, where $\mathrm{m}_{\mathrm{i}}$ is the lumped mass at the ith floor; $\sigma_{\mathrm{xi}}=$ $\mathrm{K}_{\mathrm{xi}} / \mathrm{K}_{\mathrm{x} 1}$ and $\sigma_{\theta \mathrm{i}}=\mathrm{K}_{\theta i} / \mathrm{K}_{\theta 1}$, where $\mathrm{K}_{\mathrm{xi}}$ and $\mathrm{K}_{\theta \mathrm{i}}$ are the translational and torsional storey stiffnesses, the latter defined about the floor centre of mass. For this special class of building, the proportional stiffness characteristics can be expressed as $\sigma_{\mathrm{xi}}=$ $\sigma_{\theta i}(i=1,2, \ldots, N=20)$. It is important to note that the assumed equality between $\sigma_{\mathrm{xi}}$ and $\sigma_{\theta \mathrm{i}}$ leads to the result that the parameter $R_{f l}$, as defined in the following section, is equal to the ratio of the uncoupled torsional frequency to the uncoupled translational frequency, for corresponding pairs of all the $2 \mathrm{~N}$ modes of the $\mathrm{N}$-storey building.

\section{System Parameters}

The parameter $e_{r}=e / r$ is the characteristic static eccentricity ratio, where $r$ is the mass radius of gyration of each floor, taken about the centre of mass. For the equivalent uncoupled multistorey building, $\mathrm{e}_{\mathrm{r}}=0$ for all floors. The frequency parameters $f_{x 1}=(1 / 2 \pi)\left(K_{x 1} / m_{1}\right)^{1 / 2}$ and $R_{f 1}=\left(K_{\odot 1} / r^{2} K_{x 1}\right)^{1 / 2}$ are the uncoupled translational frequency and the corresponding uncoupled torsional to translational frequency ratio, respectively, and are defined for the first storey assuming that it is, hypothetically, isolated from the rest of the building. A realistic numerical value for the fundamental natural frequency $f_{x M}$ of the multistorey building is prescribed by the empirical codified relation$\operatorname{ship}[13] f_{\mathrm{xM}}=(10 / \mathrm{N}) \mathrm{Hz}$.

The response parameter of primary interest in the study of torsional coupling effects in the elastic range of earthquake structural response is the dimensionless ratio of the mean peak coupled to uncoupled torque response $T_{\mathrm{Si}} / \mathrm{eV}_{\text {oxi }}$, where $\mathrm{V}_{0 \mathrm{xi}}$ is the dynamic shear force for storey i of the equivalent uncoupled multi-storey building, and $\mathrm{T}_{\mathrm{Si}}$ is the dynamic torque for storey $i$, calculated about the centre of stiffness. For floor $i$, the response ratio given above represents the dynamic amplification of eccentricity at that floor.

The structural parameters which influence the response parameter defined above can be reduced $[3,7]$ to $\mathrm{e}_{\mathrm{r}}, \mathrm{R}_{\mathrm{f} 1}, \mathrm{f}_{\mathrm{xM}}, \mu_{\mathrm{i}}$ and $\sigma_{\mathrm{xi}}$, assuming that the modal damping is constant for all modes. The damping is taken to be $5 \%$ of critical damping, a value which is representative of prototype buildings of the type studied herein.

In this study, the values of $e_{5}, R_{n}$ and $f_{x M}$ (for $N=20$ ) are taken to be $0.1,1.1$ and $0.5 \mathrm{~Hz}$, respectively. The results of analyses of single storey buildings $[1,12]$ have shown that this combination of $\mathrm{e}_{\mathrm{r}}$ and $\mathrm{F}_{\mathrm{n}}$ leads to significant torsional coupling effects, particularly in relation to the displacements of critical edge elements of the structure resulting from a combination of dynamic shear and torque loadings.

\section{Effect of Vertical Irregularities}

\section{Definitions}

To investigate the effect of the vertical distribution of storey mass, $\mu_{\mathrm{i}}$, on the amplification of storey dynamic eccentricity, $\mathrm{T}_{\mathrm{Si}} / \mathrm{eV}_{0 \mathrm{xi}}$, for the 20-storey model, the translational stiffness distribution, $\sigma_{\mathrm{xi}}$, is equated to unity. Three realistic vertical mass distributions are considered (see Fig.2).

It is noted that the factor of 5 , by which the mass of a heavy floor in distributions (2) or (3) is greater than the mass of a typical floor, represents an extreme case of vertical irregularity.

To examine the effect of variation in the vertical distribution of translational stiffness, $\sigma_{\mathrm{xi}}$, on the amplification of storey dynamic eccentricity for the representative 20 -storey model, a uniform mass distribution is assumed and three translational stiffness distributions are considered (see Fig.3). 
(1)

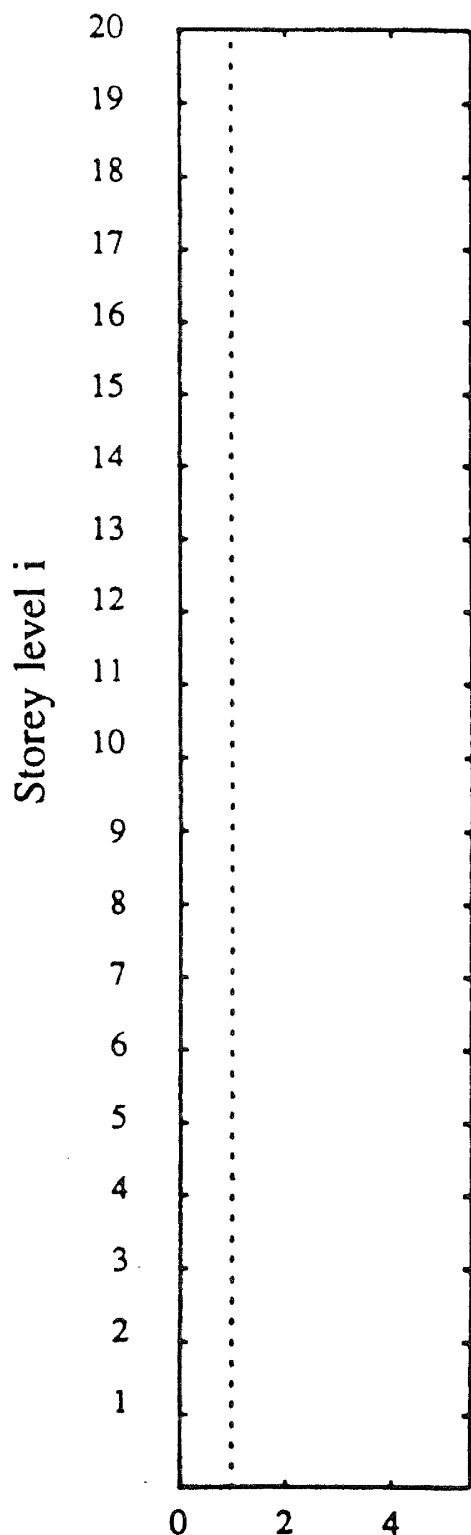

(2)

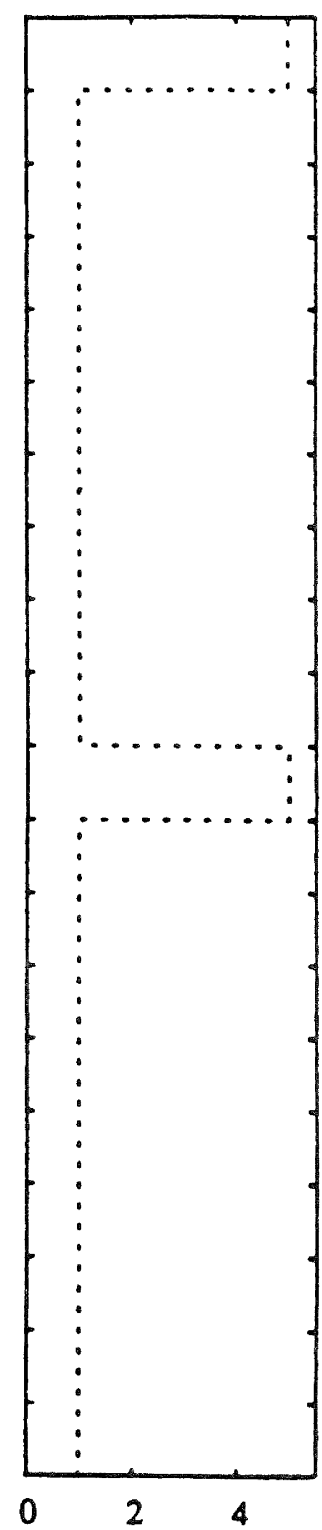

(3)

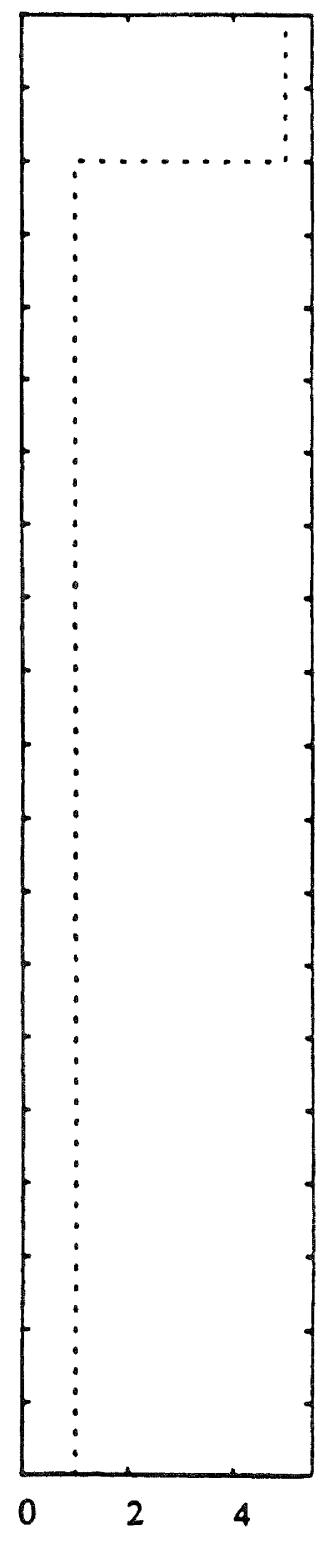

Normalised mass distribution $\mu_{\mathrm{i}}$

Figure 2 Vertical distributions of mass for a 20-storey building;
(1) uniform
(2) heavy floors at the 10th and 20th levels,
(3) heavy floors at the 19th and 20th levels. 
(i)

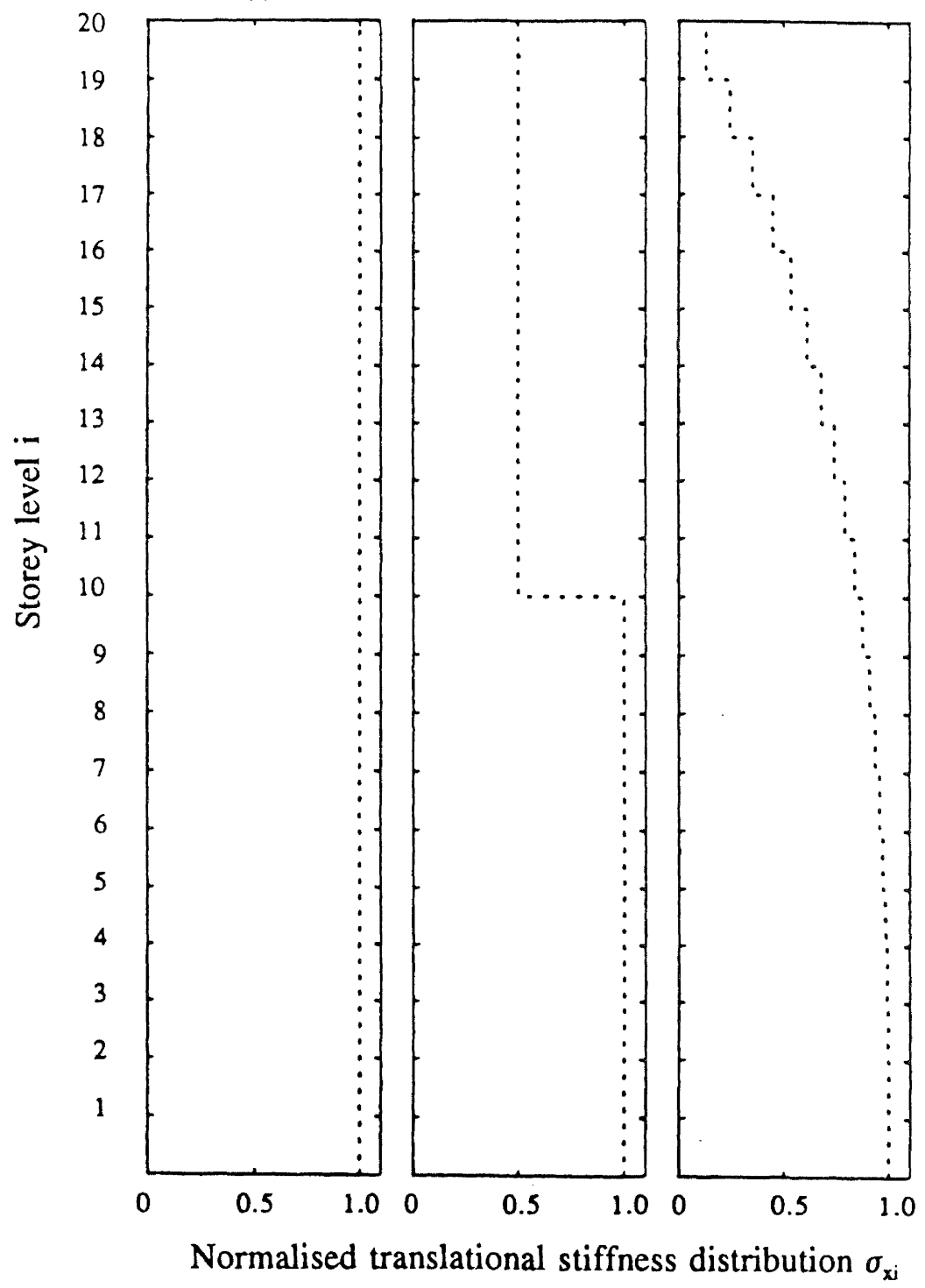

Figure 3 Vertical distributions of translational stiffness for a 20-storey building;

(i) uniform

(ii) one-step stiffness reduction

(iii) gradually tapered

The normalised storey stiffnesses, $\sigma_{\mathrm{xi}}$, for distribution pattern (iii) are estimated by consideration of the conditions of static equilibrium for the uncoupled building model. Using the vertical distribution recommended by the Uniform Building Code, 1985 version [13] for the equivalent static seismic forces, and imposing a condition of equal inter-storey drifts, the vertical distribution of translational stiffness can be expressed [7] in terms of the codified distribution coefficients for the design lateral forces acting at the various floor levels.

\section{Results}

The variation of the dynamic amplification of eccentricity with storey level for the three mass distribution patterns is shown in Fig.4(a). The results are compared with the values obtained from analysis of the equivalent single storey building model, having the same values of $e_{r}, R_{f l}$ and damping. The uncoupled translational frequency of the equivalent single storey model is taken to be $f_{x 1}$, as defined above. Fig.4(b) shows the amplification factors expressed as percentages of the values obtained for the uniform distribution. 
(a)

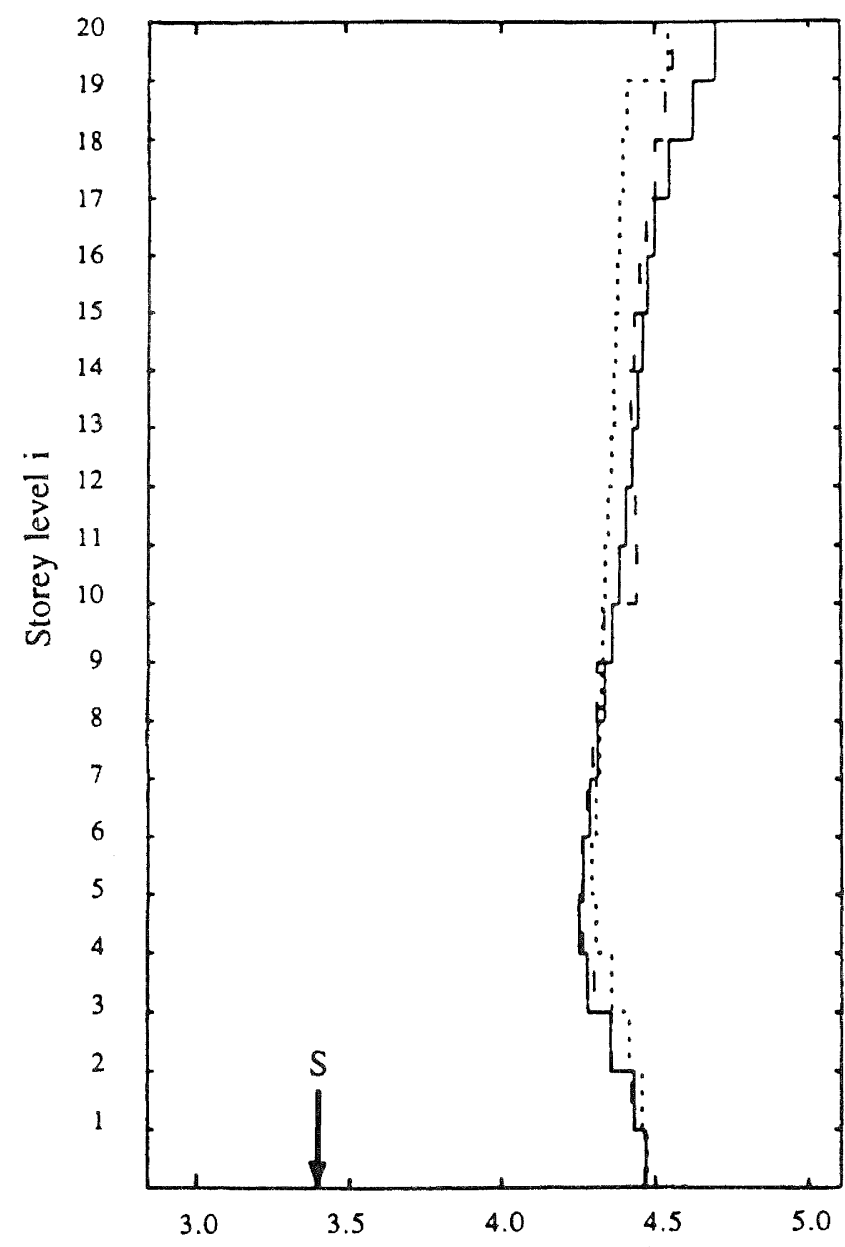

(b)

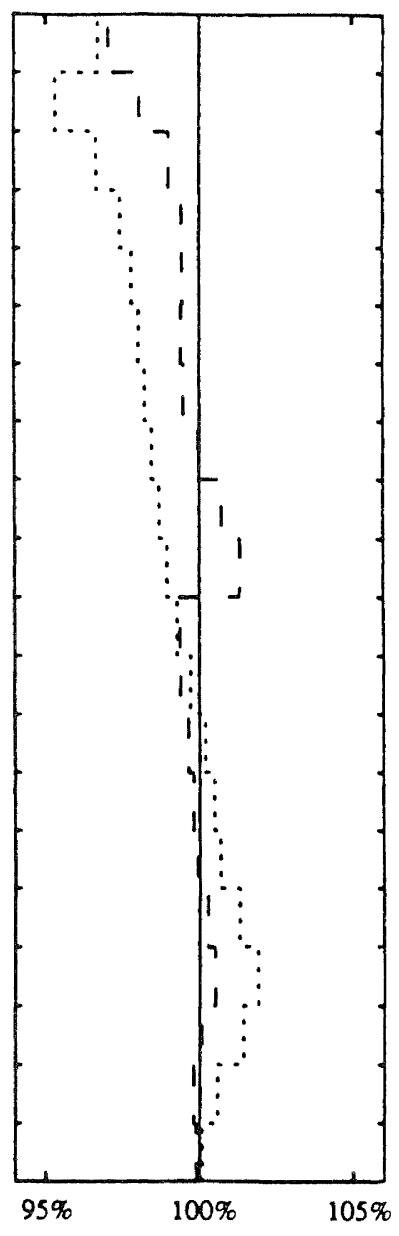

Amplification of eccentricity $\mathrm{T}_{\mathrm{si}} / \mathrm{eV}_{0 \mathrm{xi}}$

(1) $\quad-\quad-(2)$

$S=$ Single storey model

Figure 4 Variation of the dynamic amplification of eccentricity with storey level, given as

(a) actual values for the three mass distributions and for the equivalent single storey model,

(b) a percentage of the values for the uniform distribution (1)

Fig.4(a) indicates that the dynamic eccentricity distribution patterns are essentially the same for the three cases. The maximum dynamic eccentricity amplification for the uniform mass distribution (at the top floor) is greater than the maxima for the two irregular distributions. The accuracy of the single storey approximation varies with floor level. Clearly this approximation significantly underestimates the dynamic eccentricity amplification for this representative multi-storey building. This aspect is further examined in reference [3]. Fig.4(b) shows that the percentage difference of the results for mass distributions (2) and (3) are within $+2 \%$ to $-5 \%$ of those for the uniform distribution (1).
For all three stiffness distributions the maximum dynamic eccentricity amplification (Fig.5(a)) occurs at the top floor, with the gradually tapered distribution giving the largest maximum value. Again, the single storey approximation significantly underestimates the eccentricity amplification. Fig.5(b) shows that the dynamic eccentricity amplification for distributions (ii) and (iii) is within $+2 \%$ to $-2 \%$ of that for distribution (i), throughout the height of the building. 
(a)

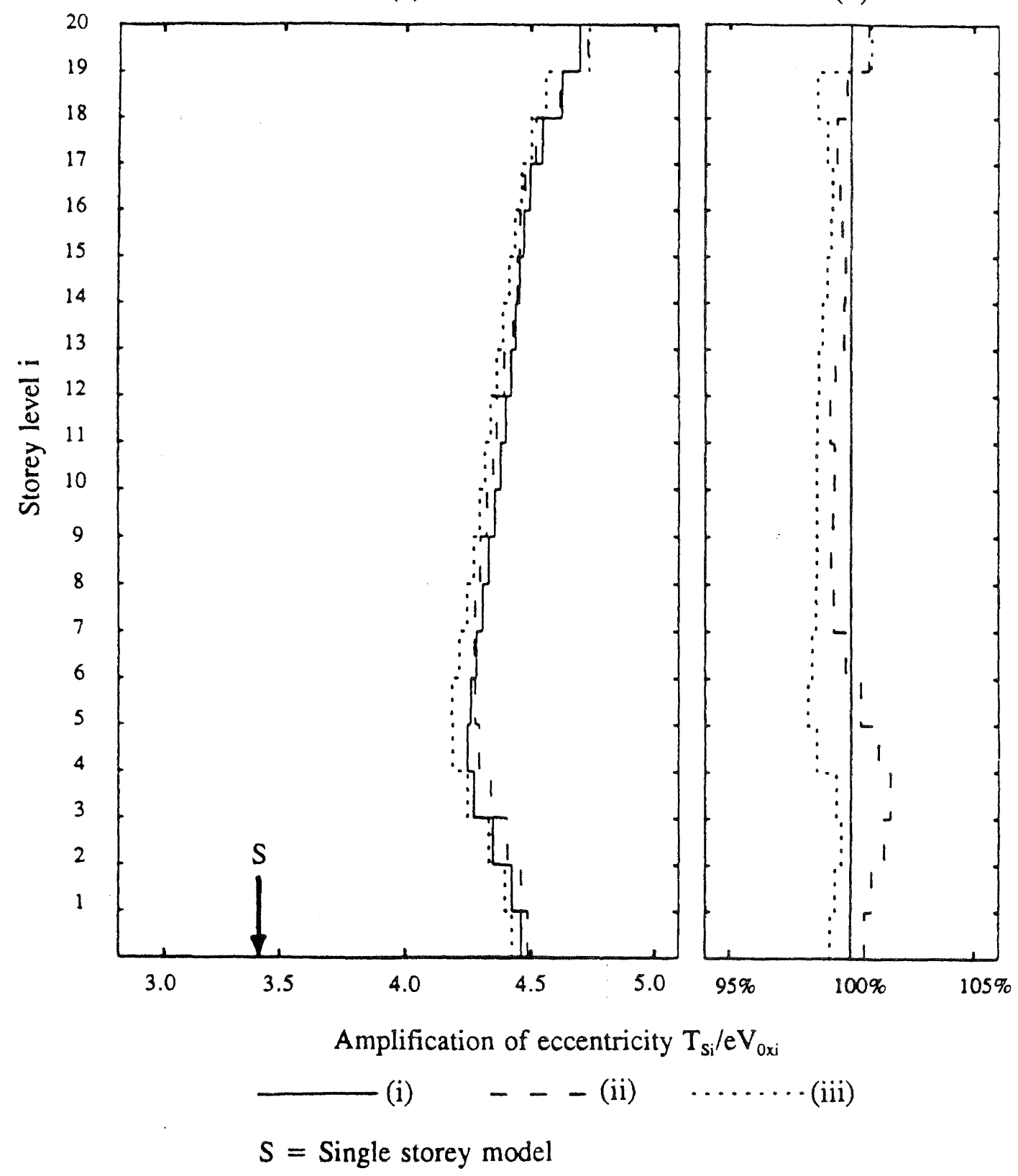

(b) 
It is evident that the variations in the normalised vertical distributions of mass and translational stiffness (which influence the spacing of the higher translational and torsional natural frequencies [7] do not have a significant effect on the amplification of the torsional response. It is therefore reasonable for the purpose of further parametric studies $[3,4]$ to adopt the uniform mass and the gradually tapered stiffness distributions as a combination which is realistic for many codedesigned buildings.

\section{CONCLUSIONS}

1) The similarities between the seismic torsional response of the special class of multi-storey building and the corresponding single storey models are only qualitative. The contribution of the higher translational and torsional modes for the multi-storey model can, in some cases, lead to significant numerical differences.

2) The distribution of torsional coupling effects is not uniform over the height of the building. The coupling effects in a given storey are dependent (amongst other factors) on its position in the building, the top floor exhibiting the most pronounced effects.

3) It is reasonable for the purpose of parametric studies of torsional coupling in multi-storey buildings to adopt the combination of a uniform vertical mass distribution and a gradually tapered vertical stiffness distribution.

\section{ACKNOWLEDGEMENT}

The financial assistance provided for Dr Rady in the form of a University of Melboume Postgraduate Scholarship is gratefully acknowledged.

\section{REFERENCES}

1. Chandler, A.M. and Hutchinson, G.L. 1986. "Torsional coupling effects in the earthquake response of asymmetric buildings", Engineering Structures 8 : 222-236.

2. Chandler, A.M. and Nichol, E.A. 1990. "Experimental evaluation of procedures for earthquake analysis of torsionally asymmetric buildings", European Earthquake Engineering 4(3) : 43-52.

3. Chandler, A.M., Hutchinson, G.L. and Rady, M.A. "Torsional coupling in multi-storey buildings with vertical irregularities : parametric study", Earthquake Engineering and Structural Dynamics (submitted for publication).

4. Chandler, A.M., Hutchinson, G.L. and Rady, M.A. "Torsional coupling in multi-storey buildings with vertical irregularities : design considerations", (in preparation).

5. Hejal, R. and Chopra, A.K. 1989. "Earthquake analysis of a class of torsionally-coupled buildings", Earthquake Engineering and Structural Dynamics 18 : 305-323.

6. Kan, C.L. and Chopra, A.K. 1977. "Elastic earthquake analysis of a class of torsionally coupled buildings", Journal of the Structural Division, American Society of Civil Engineers 103(ST4) : 821-838.

7. Rady, M.A. 1989. "A new refined approach to the formulation of the earthquake-resistant design regulations for torsionally coupled multistorey buildings". Ph.D thesis, The University of Melbourne, Australia.

8. Rady, M.A. and Hutchinson, G.L. 1988. "Evaluation of dynamic eccentricities obtained using a probabilistic approach, response spectrum methods and modern building codes", Earthquake Engineering and Structural Dynamics $16: 275-291$.

9. Stafford-Smith, B. and Vezina, S. 1985. "Evaluation of centres of resistance in multistorey building structures", Proceedings of the Institution of Civil Engineers, London 79 : 623-635.

10. Tsicnias, T.G. 1981. "Coupled lateral and torsional earthquake response of buildings with rigid floor diaphragms". Ph.D thesis, University of London.

11. Tso, W.K. and Cheung, V.W-T. 1986. "Decoupling of equations of equilibrium in lateral load analysis of multistorey buildings", Computers and Structures 23(5) : 679-684.

12. Tso, W.K. and Ying, H. 1990. "Additional seismic inelastic deformation caused by structural asymmetry", Earthquake Engineering and Structural Dynamics 19 : 243-258.

13. Uniform Building Code of America. 1985. "Section 2312 : Earthquake Regulations", International Conference of Building Officials, Whittier, California. 